\title{
Comparison of growth curve models in Japanese quail raised in cages enriched with different colored lights
}

\author{
Ufuk Karadavut ${ }^{1 *}$, Atilla Taskin ${ }^{1}$, Serdar Genc ${ }^{2}$
}

\author{
${ }^{1}$ Ahi Evran University, Department of Animal Science, Kirsehir, Turkey. \\ ${ }^{2}$ Ahi Evran University, Department of Agricultural Biotechnology, Kirsehir, Turkey.
}

\begin{abstract}
This study compared the growth curve models for the live weight and body length of Japanese quail raised under lights of various colors. The Brody, Gompertz, and von Bertalanffy growth models were used to investigate the effect of different colored lights on Japanese quail growth over a period of six weeks (1-42 days). Four lights of different colors, comprising yellow, red, blue, and white, were used in the study. According to the different light colors, the mean and standard error for the live weight and body length on day 42 were calculated as 196.09 and $3.87 \mathrm{~g}$ and 29.48 and $0.192 \mathrm{~cm}$, respectively. Furthermore, while the differences in live weight according to the color of the light being used were statistically significant on days 14,21 , and 28 , there were significant differences in body length on days $7,28,35$, and 42 , depending on the color of the light used. The highest values of $\mathrm{R}^{2}$ for body length and live weight were 0.9935 and 0.9988 ; the lowest sum of square error values for body length and live weight were 9.6588 and 10.6623 according to the Gompertz model. Test results did not reveal autocorrelation among serial data except for those grown under red colored lights.
\end{abstract}

Key Words: bird, body parametrs, environmental enrichment, led light

\section{Introduction}

Growth and development are important characteristics for all living beings. Ensuring healthy, trouble-free growth during the first stages of life is important for increased vitality in the future. For all living beings, from single-celled organisms to multicellar organisms, growth, generally speaking, means a time-dependent increase in size, weight, and number of cells. Japanese quail are frequently used in growth studies. The main reasons for this are their rapid growth rate, short generation interval, good feed efficiency, high adaptability, fast reproduction, and high disease resistance. Studies on quail are also important in that their results can be applied to other poultry (Alkan et al., 2008; Culfaci et al., 2008; Narinc et al., 2009; Abdullah et al., 2010).

Studies relating to growth generally examine timedependent changes; however, the biological interpretation

Received: May 20, 2016

Accepted: November 23, 2016

*Corresponding author: ufukkaradavut@gmail.com

http://dx.doi.org/10.1590/S1806-92902017001100002

How to cite: Karadavut, U.; Taskin, A. and Genc, S. 2017. Comparison of growth curve models in Japanese quail raised in cages enriched with different colored lights. Revista Brasileira de Zootecnia 46(11):839-846.

Copyright (C) 2017 Sociedade Brasileira de Zootecnia. This is an Open Access article distributed under the terms of the Creative Commons Attribution License (http://creativecommons.org/licenses/by/4.0/), which permits unrestricted use, distribution, and reproduction in any medium, provided the original work is properly cited. of mathematical expressions and functions is also important in determining these changes (Karadavut et al., 2010). Results that cannot be biologically interpreted limit the benefits and successes of a study. Mathematical models developed with the use of growth data collected at different periods enable biological processes to be explained and the necessary growth-related assessments to be made (Behr et al., 2001). Growth models may also provide valuable data regarding the growth potential of the animals studied (Tarhan and Sezer, 2004). Nonetheless, it is also important to increase the reliability of such data. To this end, it is necessary to improve the raising conditions of the animals (Oguz and Turkmut, 1999). This is because environmental conditions, as well as rapid changes in these conditions, can have a positive as well as a negative impact on growth (Barbato, 1991). Anthony et al. (1986) described how an ideal growth model should be able to assess all aspects relating to growth. Karadavut et al. (2014) demonstrated that growth curves for live weight could be used as selection criteria for quail. Colak et al. (2006) explained that growth models not only provide information regarding the future growth and development of animals, but also enable raisers to identify and separate the animals to be used for breeding at earlier ages, determine the suitable cutting age, and assess the general health of the animals.

Curves obtained through animal growth data generally have a sigmoidal structure. Sigmoidal growth consists of two stages. The first stage is expressed as the inflection 
point. At this stage, the growth rate is maximum and then begins to decrease. The growth rate continues to decrease in the second stage until the point of zero growth. This stage is expressed as asymptotes (Ratkowsky, 1990; Bilgin and Esenbuga, 2003). The asymptote value indicates the highest value that can be theoretically reached for an individual when all conditions are suitable.

It is known that in poultry, many physiological processes are affected by light (Svobodová et al., 2015). Artificial lighting used in modern chicken coops is an important environmental factor that affects many production-related parameters (depending on duration of lighting, color, and intensity of light, etc.) (Rozenboim et al., 2004; Er et al., 2007). Cimrin and Tunca (2013) noted that green light in quail raising has a positive and significant effect on vigor, as well as on other characteristics.

In this study, Japanese quail were raised in cages enriched with yellow, red, blue, and white colored LED lights. The aim of the study was to estimate the timedependent changes in the live weight and body length of these quail through Brody, Gompertz, and von Bertalanffy growth models.

\section{Material and Methods}

The study was conducted in Kirsehir, Turkey $\left(39^{\circ} 8^{\prime} 45^{\prime \prime} \mathrm{N}\right.$ and $\left.34^{\circ} 9^{\prime} 34^{\prime \prime} \mathrm{E}\right)$. It was approved by the local Ethics Committee for Animal Experimentation (case no. 11/12/2015-4/08). The study material consisted of 320 newly hatched (one-day-old) Japanese quail chicks of mixed sex (male and female). These chicks were hatched in four different incubators. The quail from which the chicks were obtained were 16 weeks old; no specific selection method was employed when choosing the chicks. The chicks were randomly divided into four groups of 80 chicks each. Each group was then divided into four subgroups of 20 by being placed in a four-level cage with one section per level, with one sub-group being located in each level or section. The sub-groups thus constituted four duplicates for the same groups. Cage section dimensions were $50 \times 80 \times 37 \mathrm{~cm}(\mathrm{~L} \times \mathrm{W} \times \mathrm{H})$, with 20 quail per section $\left(200 \mathrm{~cm}^{2} /\right.$ bird). During the study, the animals were fed from day 1 to day 42 with a commercial broiler feed (corn-soybean-based diet) containing $23 \%$ crude protein and $3200 \mathrm{kcal} / \mathrm{kg}$ metabolic energy. Live weight and body length data from days $1,7,14,21,28,35$, and 42 were used in determining the growth curves. The live weight of the chicks on days $1,7,14,21,28,35$, and 42 was measured weekly using an electronic precision scale, while the body length (distance between the beak and tail of the birds) was measured using a digital compass. The chicks were given ad libitum access to food and water throughout the study period. The temperature of the growth environment was maintained at $36{ }^{\circ} \mathrm{C}$ for the first week of the study and then gradually decreased to room temperature in the subsequent weeks (Karadavut et al., 2014).

Cage sections and hatcheries were lit using white LED (400-700 nm), red LED (620 nm), yellow LED (580 nm), and blue LED (455 nm) strips. Lighting was applied for $24 \mathrm{~h}$ a day, with the light intensity at the level of the heads of quail being maintained as 10 lux. The light-proof cage dividers were used to prevent mixing of light. In addition, the lighting methods and periods ( $24 \mathrm{~h}$ a day) used in the cages were also applied in the hatcheries.

The study was established using the repeated measures experimental design. In this design, analysis of variance was performed. This study was conducted as a single factor trial. Differences between groups were determined using the DUNCAN test.

The Brody, Gompertz, and von Bertalanffy growth curve models were used to determine the model that best defines growth. The growth curve models used in the study were as follows (Draper and Smith, 1981):

Brody Model: $Y=a \cdot\left(1-b e^{(-k t)}\right)$

Gompertz Model: $Y=a e^{-b e^{(-k t)}}$

Von Bertalanffy Model: $Y=L_{\infty}\left[1-e^{\left(-k\left(t-t_{0}\right)\right)}\right]$

In the equations above, $Y$ represents the specific characteristic being investigated. Therefore, $Y$ represents "live weight" when the examined characteristic is live weight, and "body length" when the examined characteristic is body length; $a$ and $L_{\infty}$ represent the theoretical upper asymptote value; $b$ represents the initial weight or length; $k$ represents the growth amount; $e$ represents the natural $\log$ base, which is 2.718; and $t$ represents time.

When comparing the models, the coefficient of determination $\left(\mathrm{R}^{2}\right)$ and the error sum of squares were used. It can be postulated that the coefficient of determination $\mathrm{R}^{2}$ ranges from 0 to 1 . The results of the model are not suitable for the data obtained if close to zero. If the result is close to 1 , the model is appropriate. As the success of the model increases, the error sum of squares comes closer to zero. In addition, it is verified whether there are any relationships between the consecutive values of the error term. In the study, the Durbin-Watson test statistic (Draper and Smith, 1981) was employed. This statistics can be expressed with the following equation: 


$$
d=\frac{\sum_{t=2}^{n}\left(e_{t}-e_{t-1}\right)^{2}}{\sum_{t=1}^{n} e_{t}^{2}}
$$

In the equation above, $e_{t}$ represents the $t$-th error term obtained for $t=1,2, \ldots, \mathrm{n}$ through the least square regression. The $d$ value calculated with the equation was compared with the two critical benchmark values, dL and $\mathrm{dU}$. Comparisons were performed as shown below (Koutsoyiannis, 1989):

If $0<\mathrm{dL}$, there is a positive autocorrelation.

If $\mathrm{dL} \leq \mathrm{d} \leq \mathrm{dU}$, an assessment cannot be made regarding the correlation.

If $\mathrm{dU}<\mathrm{d}<4-\mathrm{dU}$, there is no autocorrelation.

If $4-\mathrm{dU} \leq \mathrm{d} \leq 4-\mathrm{dL}$, an assessment cannot be made regarding the correlation.

If $4-\mathrm{dL}<\mathrm{d}<4$, there is negative autocorrelation.

The presence of an autocorrelation indicates a relationship between two consecutive values. In such cases, overlooking the autocorrelation will cause estimated coefficient variance values to be lower or much higher than the actual variance value. This will cause variance values to be skewed and inconsistent. For this reason, it is important to take autocorrelation into account. Based on the analysis results, the model with a high coefficient of determination and low error sum of squares was considered successful. The statistical software Statistica 5.0 was used.

\section{Results and Discussion}

The live weight responses of the quails subjected to the different light colors were fairly close to one another (Table 1).

While quail chicks raised under yellow light had lower initial weight than chicks raised under different colored lights, this appears not to be statistically significant; it was undoubtedly evaluated due to chance, as there had been insufficient time to affect the growth. From day 7 , they had a tendency towards similar growth. This period continued until day 28; however, although the increase in growth continued after day 28 , it was at a progressively slower rate (i.e. slowly leveled off). Growth measurements were taken as live weight. For the first three weeks, chicks grown under yellow light exhibited lower mean live weight values than the chicks raised under the other light colors. In general, yellow light had the highest positive effect on the increase in live weight. As such, the use of yellow light, in particular, may be considered for ensuring continuity of growth. On the other hand, it was observed that the effect of white light on the live growth rate decreased during the fifth period. However, this difference was not statistically significant. As a result, it should be noted that continuing the use of blue light after a certain period could have a statistically significant negative effect on the live weight increase of quail chicks until day 35 . In this study, the cumulative growth was evaluated to assess the effects of light color in a certain period. Percentage growth could be better for measuring.

A review of studies investigating the effect of light colors on body length revealed a high level of periodic differences. For this reason, it is difficult to state categorically which light color has the most effect on body length. Light colors among groups were insignificant $(\mathrm{P}>0.05)$ during the first, third, and fourth periods. However, by closely monitoring growth and development and conducting additional studies, it might be possible to gain a better understanding and control of this effect, especially using different colors in different periods of growth. The results of the present study can be applied in a practical way on farms with good management.

When an attempt is made to model the growth of any living thing in a biological system, there are three different cases in terms of growth rate: firstly, a fixed rate of growth; secondly, the continuously increasing or decreasing rate of growth; and thirdly, the variable growth rate. In this study, the shape of the growth curve of quail changed according to different colors. Different light colors should be studied in detail to decide which color is more effective on the growth of birds.

Results of ANOVA, especially for the live weight, the differences among colors for 14, 21, and 28 days were significant. In these periods, growth under colored lights is significantly influenced. For body length, days 7, 28, 35 , and 42 showed significant differences. Accordingly, as time progresses, the body length is affected more than growth or live weight increases. Similar effects were shown with yellow and red light, except for day 28. In this week, differentiation can be seen due to environmental factors. The fixed growth rate can occur in certain periods for certain characteristics of quails. Generally, the growth was not constant throughout the life of quail as reported by Efe (1990), Kshirsagar and Smith (1995), and Kocabaş et al. (1997). Linear models are inadequate for the evaluation of quail (Perotto et al., 1992); because of this, the non-linear model was used in this study.

In a previous study, Phogat et al. (1985) determined that Japanese quail raised under green and blue lights had higher live weights than those raised under white and red lights. Rozenboim et al. (1999) found that green light stimulated growth at earlier ages, while blue light stimulated growth at 
later ages. Halevy et al. (1988) determined that green light had a noticeably more positive effect on muscle growth than the other light colors. Spais et al. (1985), on the other hand, described that the light source did not have any effect on live weight in Japanese quail. However, they noted that light source had a considerably important effect on feed utilization rates. In a study on quail raised under white, red, and green lights, Sarica (1998) observed that light had a positive and significant effect on growth.

Both the live weights and body lengths of the animals showed a rapid increase in the first period (or first weeks) of the study (Figure 1). Nevertheless, in the ensuing weeks, the growth rate gradually began to slow down, depending on the color of the light. Woodard et al. (1969) previously investigated the effect of light color and intensity of quail growth. They demonstrated that females raised under blue lights with an intensity of $\geq 10$ lux until the fifth week of life showed less growth than females grown under red and white light. It was also observed that females raised under red light also reached sexual maturity at an earlier age. Moreover, testis development in males raised under red light was three times greater compared with males raised

Table 1 - Live weight and body length values of quail according to light colors

\begin{tabular}{|c|c|c|c|c|c|c|c|}
\hline \multirow{2}{*}{ Day } & \multirow{2}{*}{ Light } & \multicolumn{3}{|c|}{ Live weight (g) } & \multicolumn{3}{|c|}{ Body length $(\mathrm{cm})$} \\
\hline & & $\overline{\mathrm{X}} \pm \mathrm{S}_{\overline{\mathrm{x}}}$ & Min. & Max. & $\overline{\mathrm{X}} \pm \mathrm{S}_{\overline{\mathrm{x}}}$ & Min. & Max. \\
\hline \multirow{6}{*}{1} & Yellow & $8.02 \pm 0.366$ & 6.03 & 9.85 & $9.25 \pm 0.267$ & 6.12 & 12.37 \\
\hline & Red & $8.06 \pm 0.412$ & 6.15 & 9.56 & $8.89 \pm 0.302$ & 6.24 & 13.02 \\
\hline & Blue & $8.12 \pm 0.318$ & 6.42 & 10.05 & $8.91 \pm 0.374$ & 5.89 & 12.13 \\
\hline & White & $8.04 \pm 0.429$ & 6.28 & 9.12 & $9.11 \pm 0.295$ & 5.66 & 10.41 \\
\hline & Mean & $8.06 \pm 0.254$ & 6.15 & 9.65 & $9.04 \pm 0.302$ & 5.98 & 11.98 \\
\hline & P-value & 0.314 & & & 0.439 & & \\
\hline \multirow{6}{*}{7} & Yellow & $29.148 \pm 0.385$ & 21.00 & 35.00 & $15.030 \pm 0.0970 \mathrm{a}$ & 13.00 & 16.06 \\
\hline & Red & $29.674 \pm 0.344$ & 21.00 & 37.00 & $15.246 \pm 0.0834 \mathrm{a}$ & 13.01 & 17.02 \\
\hline & Blue & $29.441 \pm 0.403$ & 23.00 & 38.00 & $15.352 \pm 0.0792 \mathrm{a}$ & 14.04 & 16.07 \\
\hline & White & $30.274 \pm 0.423$ & 23.00 & 36.00 & $15.019 \pm 0.0988 \mathrm{~b}$ & 13.07 & 17.04 \\
\hline & Mean & $29.63 \pm 0.386$ & 22.00 & 36.50 & $15.16 \pm 0.0812$ & 13.28 & 16.55 \\
\hline & P-value & 0.252 & & & $0.027 *$ & & \\
\hline \multirow{6}{*}{14} & Yellow & $71.750 \pm 0.722 \mathrm{a}$ & 61.00 & 82.00 & $23.310 \pm 0.0918$ & 21.70 & 24.70 \\
\hline & Red & $69.874 \pm 0.654 \mathrm{a}$ & 53.00 & 84.00 & $23.302 \pm 0.0685$ & 21.60 & 24.60 \\
\hline & Blue & $67.090 \pm 0.783 b$ & 52.00 & 85.00 & $23.278 \pm 0.121$ & 21.10 & 29.00 \\
\hline & White & $72.061 \pm 0.799 a$ & 58.00 & 91.00 & $23.345 \pm 0.0780$ & 21.40 & 24.20 \\
\hline & Mean & $70.19 \pm 0.744$ & 56.00 & 85.50 & $23.31 \pm 0.117$ & 21.45 & 25.63 \\
\hline & P-value & $0.00 * *$ & & & 0.963 & & \\
\hline \multirow{6}{*}{21} & Yellow & $113.48 \pm 1.00 \mathrm{a}$ & 97.00 & 129.00 & $26.813 \pm 0.118$ & 24.30 & 28.20 \\
\hline & Red & $109.02 \pm 1.58 \mathrm{a}$ & 54.00 & 135.00 & $26.670 \pm 0.103$ & 23.90 & 28.70 \\
\hline & Blue & $102.80 \pm 1.73 b$ & 56.00 & 131.00 & $26.492 \pm 0.107$ & 24.20 & 28.50 \\
\hline & White & $108.67 \pm 2.08 \mathrm{ab}$ & 48.00 & 130.00 & $26.756 \pm 0.133$ & 23.40 & 28.60 \\
\hline & Mean & $108.49 \pm 1.64$ & 63.75 & 131.25 & $24.68 \pm 0.116$ & 23.95 & 28.50 \\
\hline & P-value & $0.00 * *$ & & & 0.233 & & \\
\hline \multirow{6}{*}{28} & Yellow & $154.16 \pm 1.45 \mathrm{a}$ & 132.00 & 180.00 & $28.731 \pm 0.190 \mathrm{a}$ & 25.20 & 35.00 \\
\hline & Red & $149.42 \pm 1.68 \mathrm{a}$ & 121.00 & 175.00 & $28.990 \pm 0.142 b$ & 25.10 & 31.50 \\
\hline & Blue & $143.83 \pm 1.31 b$ & 127.00 & 170.00 & $29.538 \pm 0.109 a$ & 26.90 & 31.40 \\
\hline & White & $148.33 \pm 2.25 \mathrm{ab}$ & 135.00 & 170.00 & $30.176 \pm 0.178 \mathrm{a}$ & 28.60 & 31.40 \\
\hline & Mean & $148.94 \pm 1.73$ & 128.75 & 173.75 & $29.36 \pm 0.196$ & 26.45 & 32.33 \\
\hline & P-value & $0.00 * *$ & & & $0.00 * *$ & & \\
\hline \multirow{6}{*}{35} & Yellow & $181.67 \pm 2.50$ & 143.00 & 225.00 & $29.440 \pm 0.116 b$ & 27.40 & 31.00 \\
\hline & Red & $179.45 \pm 2.19$ & 144.00 & 219.00 & $29.598 \pm 0.091 \mathrm{ab}$ & 27.80 & 31.00 \\
\hline & Blue & $175.75 \pm 3.02$ & 143.00 & 229.00 & $29.900 \pm 0.136 \mathrm{a}$ & 28.00 & 32.40 \\
\hline & White & $173.23 \pm 2.96$ & 147.00 & 204.00 & $29.865 \pm 0.12 \mathrm{ab}$ & 28.90 & 31.20 \\
\hline & Mean & $177.53 \pm 2.87$ & 144.25 & 219.25 & $29.70 \pm 0.105$ & 28.03 & 31.40 \\
\hline & P-value & 0.172 & & & $0.019 *$ & & \\
\hline \multirow{6}{*}{42} & Yellow & $196.32 \pm 3.19$ & 153.00 & 241.00 & $29.281 \pm 0.140 \mathrm{a}$ & 26.00 & 31.90 \\
\hline & Red & $200.80 \pm 3.32$ & 141.00 & 259.00 & $29.741 \pm 0.114 \mathrm{a}$ & 28.10 & 32.00 \\
\hline & Blue & $195.34 \pm 4.73$ & 155.00 & 254.00 & $29.228 \pm 0.184 b$ & 27.10 & 31.20 \\
\hline & White & $191.90 \pm 3.88$ & 153.00 & 245.00 & $29.673 \pm 0.141 \mathrm{a}$ & 27.20 & 32.40 \\
\hline & Mean & $196.09 \pm 3.87$ & 150.50 & 248.75 & $29.48 \pm 0.192$ & 27.10 & 31.88 \\
\hline & P-value & 0.360 & & & $0.016^{*}$ & & \\
\hline
\end{tabular}

\footnotetext{
* Significant at $5 \%$ of probability.
}

** Significant at $1 \%$ of probability.

$\mathrm{a}-\mathrm{b}$ - The differences among the means of groups with different letters on the same column were statistically significant. 
under blue light. The egg yield of females raised under red light was also higher compared with females raised under blue light. Kobayashi et al. (1990) exposed one-day-old chicks to high (1620-1746 lux), medium (46-83 lux), and low (3.8-4.7 lux) intensities and reported that at the ages of two, four, six, and eight weeks, low and medium light intensities caused a significant decrease in live weight among females, while low intensity had no effect on live weight and vigor among males.

The Brody model was less effective compared with the other models in explaining/estimating both live weight and body length (Table 2). On the other hand, the Gompertz

Table 2 - Comparison criteria for live weight and body length

\begin{tabular}{|c|c|c|c|c|c|c|}
\hline \multirow[t]{2}{*}{ Model } & \multicolumn{2}{|c|}{$\mathrm{R}^{2}$} & \multicolumn{2}{|c|}{$\begin{array}{c}\text { Error sum of } \\
\text { squares }\end{array}$} & \multicolumn{2}{|c|}{ DW } \\
\hline & BL & LW & $\mathrm{BL}$ & LW & BL & LW \\
\hline Brody & 0.9612 & 0.9752 & 223.8554 & 219.3623 & 1.91 & 1.85 \\
\hline Gompertz & 0.9935 & 0.9988 & 9.6588 & 10.6623 & 1.96 & 2.01 \\
\hline Von Bertalanffy & 0.9746 & 0.9849 & 24.2553 & 52.1418 & 1.92 & 1.88 \\
\hline
\end{tabular}

$\mathrm{R}^{2}$ - coefficient of determination; BL - body length (cm); LW - live weight (g); DW Durbin-Watson value. model that showed a better fit to the data was comparatively better with regards to the coefficient of determination, error sum of squares, and the Durbin-Watson value according to $\mathrm{R}^{2}$ and SSE values (Table 3 ). The predictive power and effectiveness of this model were high. No autocorrelation was observed with respect to mean live weight and body length values, which indicated that the mean data were reliable and valid.

As an indicator of growth and development, $b$ parameter is important. It provides information about the live weight of the ripening period and maturity. Estimating small values for the $b$ parameter expresses late maturation and high adult weight (Hyankova et al., 2001) and high b values represent the early ripening and lower adult weight (Alkan et al., 2008). In our study, b estimates for yellow light were higher than for the other colors $(\mathrm{P}<0.05)$. According to this, yellow lights were considered to enhance the early ripening periods. In particular, Brody and Von-Bertalanffy had b value higher than that of Gompertz model. This shows that the Gompertz model predicts more successfully in the early stages of growth.

Table 3 - Comparison criteria for the different light colors

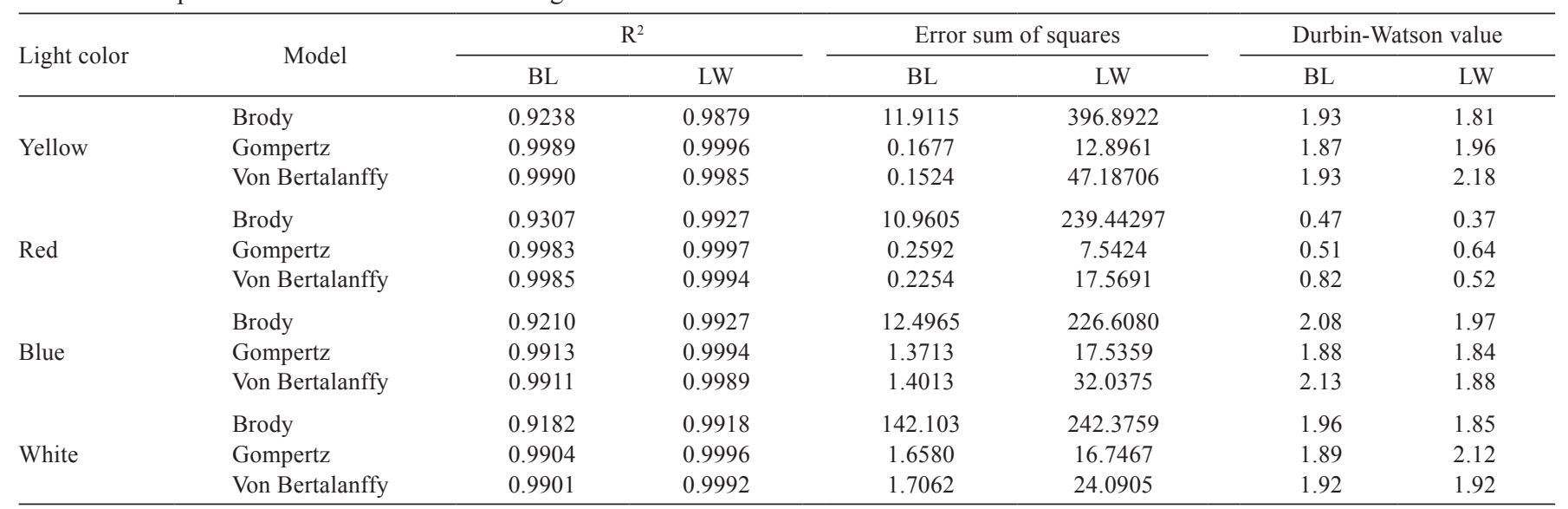

$\mathrm{R}^{2}$ - coefficient of determination; BL - body length (cm); LW - live weight (g).

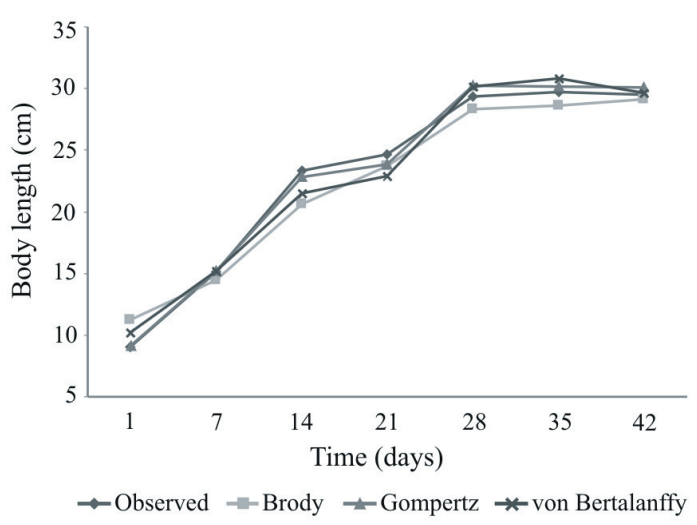

(a)

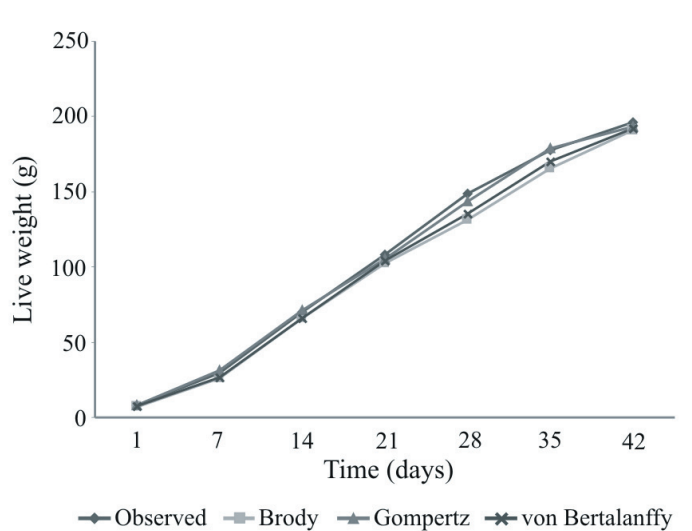

(b)

Figure 1 - Change in body length (a) and live weight (b) according to days and description of the model. 
The Gompertz model was more effective than the other models in determining live weight under all colors of light (Table 3). On the other hand, the Brody model had a lower predictive power than the other models. The results for body length were similar to those obtained for live weight. Despite the small increase in the coefficient of determination, it exhibited better performances under yellow and red lights. Similarly, the Gompertz model is recommended by Grossman and Koops (1988) in consideration with some other criteria.

In autocorrelation studies, $d$ values always vary between 0 and 4 (Durbin and Watson, 1971). According to autocorrelation results, the $\mathrm{d}$ value was in the region of 2 , which indicated the absence of any autocorrelation. A Durbin-Watson value below 1 is indicative of a problem concerning the study data; this is because a small $d$ value shows that consecutive error terms are quite close to one another in comparison to the mean and that there is, consequently, a positive relationship among them. In other words, it indicates the presence of a positive autocorrelation. In this study, a relationship between the error terms of both

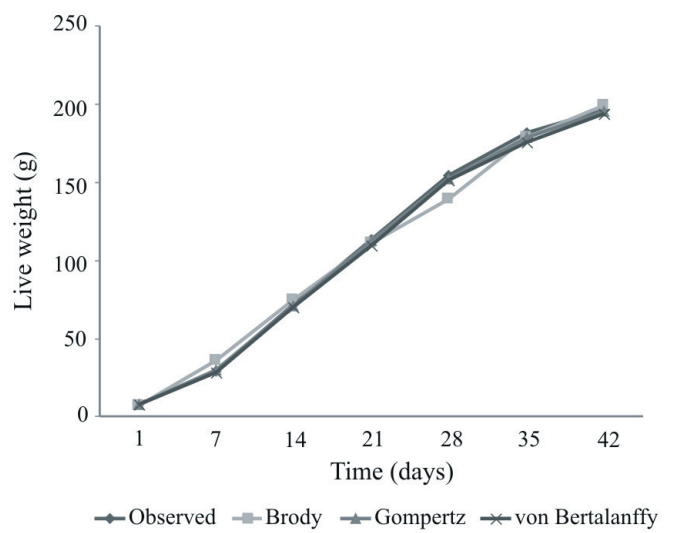

(a)

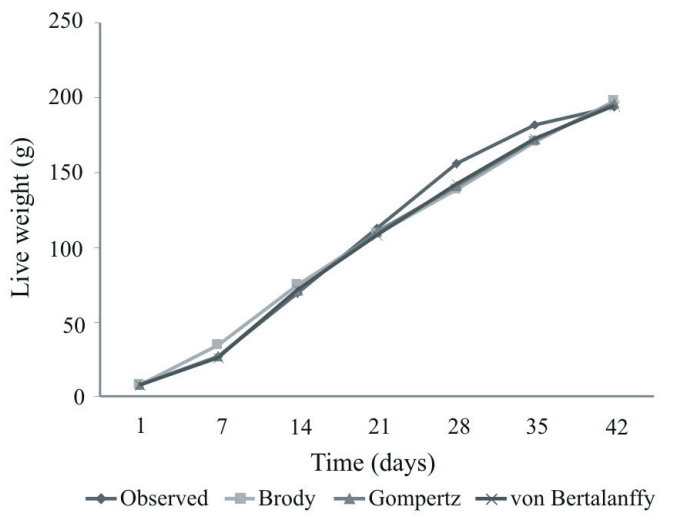

(c) the live weight and the body length were identified under all lights, except the red light. Conversely, an autocorrelation was identified for both characteristics under red light. As such, it is possible to speak of a problem and inadequacy concerning the model estimations performed for red light. It was also noteworthy that this autocorrelation was observed in all the models used for evaluating data obtained from quail grown under red lights. In this study, autocorrelation was not seen except under red light. There are positive autocorrelations under red lights. In cases of positive or negative autocorrelation, it would have reduced the success of the model (Zhang, 1994; Hamzacebi et al., 2009).

The Brody model provided a sum of square error value of 396.8922 for live weight, which was higher than the value obtained with the other models. Compared with the other models, slightly lower coefficient of determination values under all light colors indicated that this model was not suitable. In this context, it was determined that the best results were obtained with the Gompertz model from quail chicks raised under red and yellow lights. The poorest estimations were observed with the Brody model.

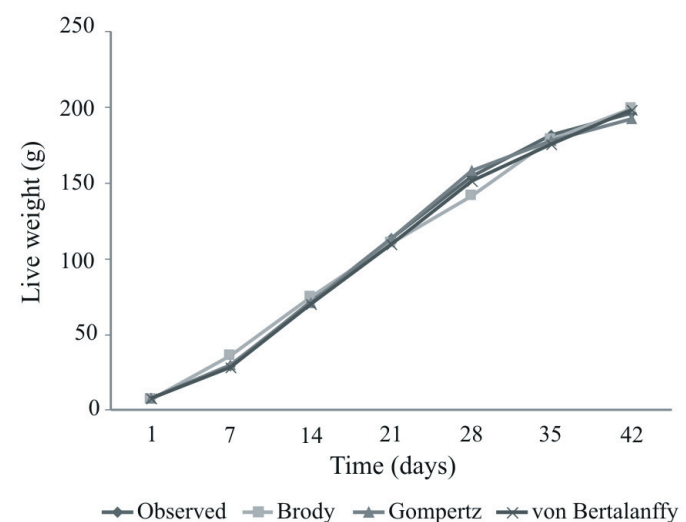

(b)

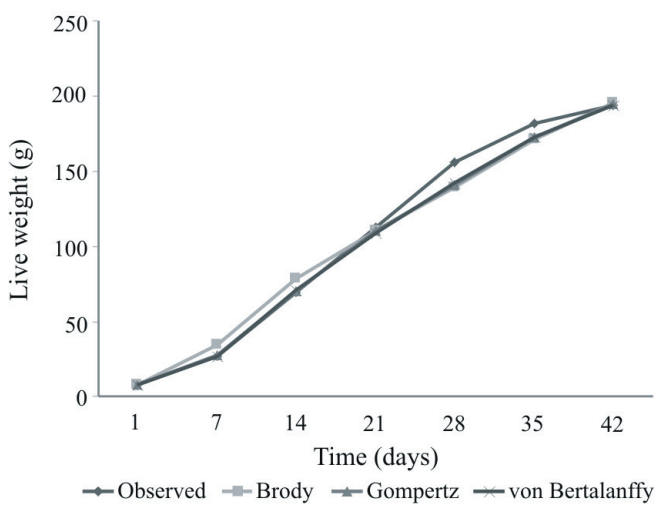

(d)

Light colors: a - yellow; b - red; c - blue; d - white.

Figure 2 - Live weight estimation curves obtained through three different growth curve models, according to the colors of light being applied. 


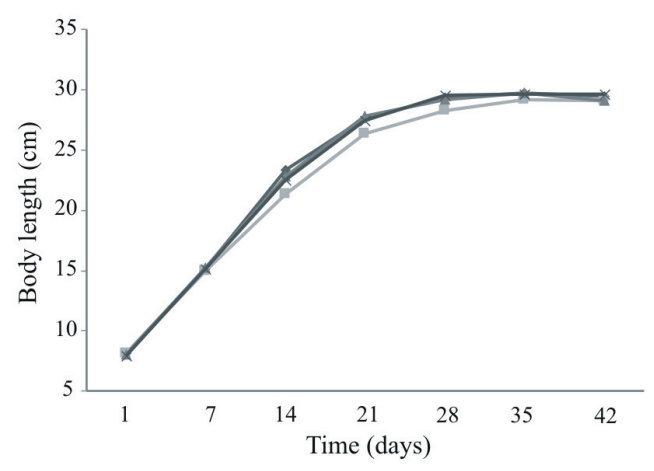

$\rightarrow$ Observed $\rightarrow$ - Brody $\rightarrow$ Gompertz $*$ von Bertalanffy

(a)

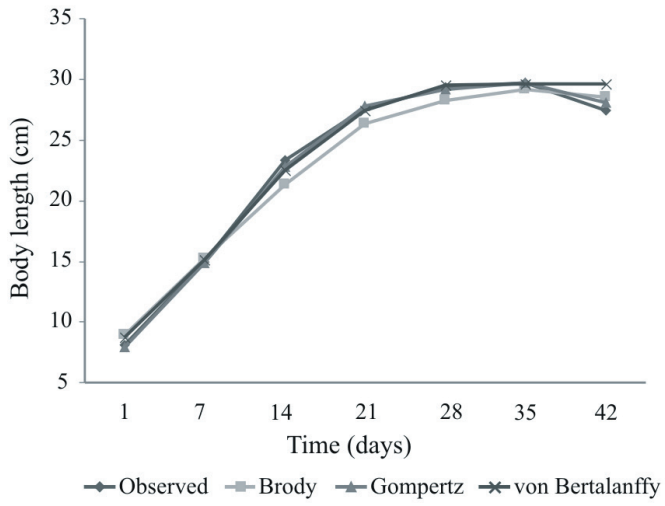

(c)

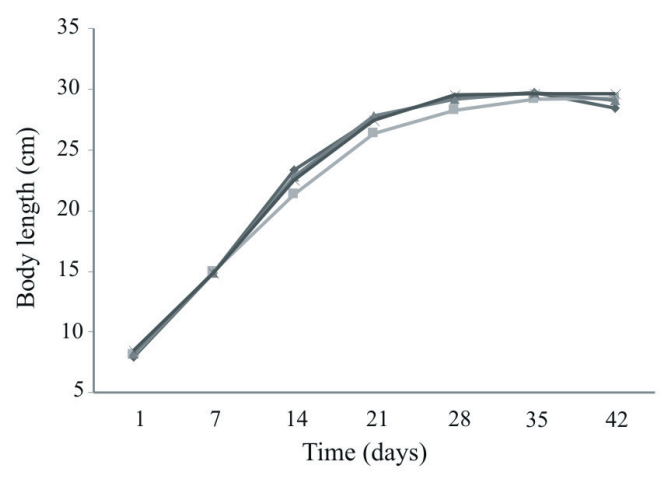

$\rightarrow$ Observed $=$ - Brody $\leadsto$ Gompertz $*$ von Bertalanffy

(b)

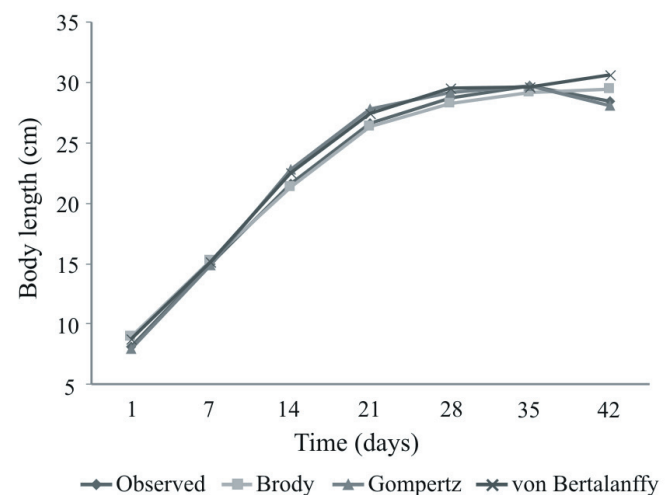

(d)

Light colors: a - yellow; b - red; c - blue; d - white.

Figure 3 - Body length estimation curves obtained through three different growth curve models, according to the colors of light being applied.

Many researchers have reported differences in terms of live weight and body length (Toelle et al., 1991; Aggrey, 2002; Sezer et al., 2006).

An evaluation of the quail body lengths indicates that the Durbin-Watson value was below 1 for quails raised under red light. As such, it is possible to say that there were significant relationships between the errors of the body length data obtained from animals raised under red light. With regards to the error sum of squares, greater deviations were observed in data obtained from animals raised under blue and white lights. As selection criteria, higher coefficient of determination, lower error sum of squares, and no autocorrelation were consequently more valid. They were therefore more successful in estimating body length.

The Gompertz model exhibited the best performance in estimating live weight under all colors of light, while the Brody model provided less accurate live weight estimations than the von Bertalanffy model (Figure 2a, b, c, d).

The results obtained for body length were roughly parallel to the results for live weight. Similarly, for all of the light colors, the models provided higher estimates than the actual values. Estimations with the Brody model were comparatively lower than the estimations with the von Bertalanffy and Gompertz models (Figure 3a, b, c, d).

\section{Conclusions}

Monitoring certain characteristics of quail (such as live weight and body length) from the moment they hatch will assist farmers in making effective strategic decisions (e.g. decisions concerning the suitable cutting age, age for use as breeders, age when used as parent stock) in line with their objectives (e.g. the raising of breeders, broilers, or layer hens). By using the Gompertz model, businesses will be able to effectively obtain data concerning the general growth and development of quail and predict their growth and development characteristics.

\section{References}

Abdullah, A. Y.; Al-Beitawi, N. A.; Rjoup, M. M. S.; Qudsieh, R. I. and Ishmais, M. A. A. 2010. Growth performance, carcass and meat quality characteristics of different commercial crosses of broiler strains of chicken. Japan Poultry Science 47:13-21. 
Aggrey, S. E. 2002. Comparison of three nonlinear and spline regression models for describing chicken growth curves. Poultry Science 81:1782-1788.

Alkan, S.; Galic, A.; Karabag, K. and Balcioglu, M. S. 2008. Effects of selection for live weight and egg weight on hatching and 6 week body weights in Japanese quails (Coturnix coturnix japonica). Hayvansal Üretim 49:16-19.

Anthony, N. B.; Nestor, K. E. and Bacon, W. L. 1986. Growth curves of Japanese quails as modified by divergent selection for 4-week body weight. Poultry Science 65:1825-1833.

Barbato, G. F. 1991. Genetic architecture of growth curve parameters in chickens. Theoretical and Applied Genetics 83:24-32.

Behr, V.; Hornick, J. L.; Cabaraux, J. F.; Alvarez, A. and Istasse, L. 2001. Growth patterns of belgian blue replacement heifers and growing males in commercial farms. Livestock Production Science 71:121-130.

Bilgin, O. C. and Esenbuga, N. 2003. Parameter estimation in nonlinear growth models. Hayvansal Üretim 44:81-90.

Cimrin, T. and Tunca, R. I. 2013. The effects of different methods on yield performances of Japanese quails (Coturnix coturnix japonica). Igdir University Journal of the Institute of Science and Technology 3:103-112.

Colak, C.; Orman, M. N. and Ertugrul, O. 2006. Simple linear and logistic growth model for the body measurements of simmental $\mathrm{x}$ southern anatolian red crossbred cattle. Veterinary Journal of Ankara University 53:195-199.

Culfaci, A.; Sezer, M. and Tarhan, S. 2008. The effect of restricted feeding on growth curves of Japanese quails. Research Journal of Agricultural Sciences 1:5-10.

Draper, N. R. and Smith, H. 1981. Applied regression analysis. 2nd ed. Wiley, New York.

Durbin, J. and Watson, G. S. 1971. Testing for serial correlation in least-squares regression, III. Biometrika 58:1-19.

Grossman, M. and Koops, W. J. 1988. Multiphasic analysis of growth curves in chickens. Poultry Science 67:33-42.

Efe, E. 1990. Growth curves. PhD thesis. Cukurova University, Adana, Turkey.

Er, D.; Wang, Z.; Cao, J. and Chen, Y. 2007. Effect of monochromatic light on the egg quality of laying hens. The Journal of Applied Poultry Research 16:605-612.

Halevy, O.; Biran, I. and Rozenboim, I. 1988. Various light source treatment affect body and skeleton muscle growth by affecting skeleton muscle satellite cells proliferation in broilers. Comparative Biochemistry and Physiology Part A: Molecular \& Integrative Physiology 120:317-232.

Hamzacebi, C.; Akay, D. and Kutay, F. 2009. Comparison of direct and iterative artificial neural network forecast approaches in multiperiodic time series forecasting. Expert Systems with Applications 36:3839-3844.

Hyankova, L.; Knizetova, H.; Dedkova, L. and Hort, J. 2001. Divergent selection for shape of growth curve in Japanese quail. 1. Responses in growth parameters and food conversion. British Poultry Science 42:583-589.

Karadavut, U.; Genc, A.; Tozluca, A. and Palta, C. 2010. Analysis of dry matter accumulation using some mathematical growth models in silage and seed corns. Journal of Agricultural Sciences 16:89-96.

Karadavut, U.; Sahin, A.; Taskin, A. and Akilli, A. 2014. Investigation of possibilities as selection criteria single and multiphase growth in Japanese quail (Coturnix coturnix japonica). Türk Tarım ve Doğa Bilimleri Dergisi 1:539-546.
Kshirsagar, A. M. and Smith, W. B. 1995. Growth curves. Marcel Dekker, New York, USA.

Kobayashi, S.; Itoh, R.; Okamoto, S. and Matsuo, T. 1990. Influence of light on egg production in Japanese quail under 14l: 10d and continuous lighting. Poultry Abstract 16:488.

Kocabaş, Z.; Kesici T. and Elicin, A. 1997. Akkaraman, Ivesi x Akkaraman ve Malya x Akkaraman kuzularında büyüme egrisi. Turkish Journal of Veterinary and Animal Sciences 21:267-275.

Koutsoyiannis, A. 1989. Ekonometri Kuram1, Verso Yayincilik, Cevirenler: Umit Senesen ve Gulay Gokturk Senesen, Ankara.

Narinc, D.; Aksoy, T.; Karaman, E. and Karabag, K. 2009. Effect of selection applied in the direction of high live weight on growth parameters in Japanese quails. Akdeniz Üniversitesi Ziraat Fakültesi Dergisi 22:149-156.

Oguz, I. and Turkmut, L. 1999. Japon Bıldırcınlarında Canlı Ağırlık İçin Yapılan Seleksiyonun Bazı Parametrelere Etkisi. 2. Verim Özellikleri ve Genetik Değişmeler. Turkish Journal of Veterinary and Animal Sciences 23:311-319.

Perotto, D.; Cue, R. I. and Lee, A. J. 1992. Comparison of nonlinear functions for describing the growth curve of three genotypes of dairy cattle. Canadian Journal of Animal Science 72:773-782.

Phogat, S. B.; Aggarwal, C. K. and Chopra, S. K. 1985. Effect of red and green lightly on growth of quail. Indian Journal of Poultry Science 20:126-128.

Ratkowsky, D. A. 1990. Handbook of nonlinear regression models. Marcel Dekker, New York.

Rozenboim, I.; Biran, I.; Uni, Z.; Robinzon, B. and Halevy, O. 1999. The effect of monochromatic light on broiler growth and development. Poultry Science 78:135-138.

Rozenboim, I.; Biran, I.; Chaiseha, Y.; Yahav, S.; Rosenstrauch, A.; Sklan, D. and Halevy, O. 2004. The effect of a green and blue monochromatic light combination broiler growth and development. Poultry Science 83:842-845.

Sarica, M. 1998. Isık rengi ve aydınlatma seklinin bildırcınların büyüme ve karkas özeliklerine etkileri. Turkish Journal of Veterinary and Animal Sciences 22:103-110.

Sezer, M.; Berberoglu, E. and Ulutas, Z. 2006. Genetic association between sexual maturity and weekly live-weights in layingtype Japanese quail. South African Journal of Animal Science 36:142-148.

Spais, A. B.; Yannakopoulos, A. and Tserveni-Goussi, A. 1985. Effect of ultraviolet rays-and their use in a lighting system-on the performance of quail. Helenic Veterinary Medicine 28:124-138.

Svobodová, J.; Tůmová, E.; Popelářová, E. and Chodová, D. 2015. Effect of light colour on egg production and egg contamination. Czech Journal of Animal Science 60:550-556.

Tarhan, S. and Sezer, M. 2004. A mathematical model for the feed utilization of Japanese quail. Journal of Animal and Feed Sciences 13:509-518.

Toelle, V. D.; Havenstein, G. B.; Nestor, K. E. and Harvey, W. R. 1991. Genetic and phenotypic relationship in Japanese quail. Poultry Science 70:1679-1688.

Woodard, A. E.; Moore, J. A. and Wilson, W. O. 1969. Effect of wave length of light on growth and reproduction in Japanese quail (Coturnix coturnix japonica). Poultry Science 48:118-123. doi: $10.3382 /$ ps.0480118.

Zhang, Z. 1994. Time series analysis and prediction by neural networks. Optimization Methods and Software 4:151-170. 